\title{
CARTAS DESDE LOS RINCONES DE CHILE PARA QUIENES SE ESTÁN FORMANDO EN TRABAJO SOCIAL ${ }^{1}$
}

\section{LETTERS FROM THE CORNERS OF CHILE FOR THOSE WHO ARE TRAINING IN SOCIAL WORK}

Fecha recepción: agosto de 2019 / fecha aceptación: noviembre de 2019

Sandra Iturrieta Olivares ${ }^{2}$

Cómo citar este artículo:

Iturrieta, S (2019). Cartas desde los rincones de Chile para quienes se están formando en trabajo social. Revista Pensamiento y Acción Interdisciplinaria, 5(2), 22-38. DOI: http://doi.org/10.29035/pai.5.2.22

\begin{abstract}
Resumen
En el contexto de la sociedad de la incertidumbre, de la circulación masiva de información y de la instantaneidad de las comunicaciones, que van conformando nuevas subjetividades virtuales, lo que obliga a ampliar la noción de intervención social directa, desde las relaciones cara a cara hacia la inclusión de la tecnosociabilidad, quienes se desempeñan en el campo de la intervención social directa, envían mensajes a las futuras generaciones de profesionales del trabajo social. Estos mensajes, fueron obtenidos a través de una investigación cualitativa a nivel nacional, que contempló el desarrollo de relatos de vida de tales profesionales. El sentido de sencillez, amistad y afecto, expresado en las entrevistas hacia las futuras generaciones de la profesión, permite asimilar dichos mensajes a cartas modélicas que responden al binomio maestro-discípulo y toman como función predominante la persuasiva. El presente artículo da cuenta de los valores, tradiciones profesionales y orientaciones para la acción, ofrecidas por profesionales del trabajo social a quienes actualmente conforman el mundo estudiantil de la disciplina, en una sociedad cada vez más reticular.
\end{abstract}

Palabras clave: Incertidumbre, sociedad reticular, cartas a estudiantes, trabajo social, intervención social directa e indirecta.

\footnotetext{
1 Este artículo corresponde a uno de los resultados del proyecto de investigación N¹1170220, titulado "Subjetividades con que profesionales de la intervención social directa experiencian su ejercicio laboral: aportes a la formación profesional de pregrado", que ha sido financiado por CONICYT-Chile, a quienes agradecemos tales recursos. Igualmente agradecemos los recursos otorgados por la Dirección de Investigación de la Pontificia Universidad Católica de Valparaíso, para el óptimo desarrollo de dicha investigación.

2 Trabajadora social, chilena. Doctora en ciencias sociales, Universidad de Granada, España. Magíster en el análisis de los problemas sociales de las sociedades avanzadas, Universidad de Granada, España. Post doctorado en el estudio de las ideas, Instituto de Estudios Avanzados, Universidad de Santiago de Chile. Académica de la Escuela de Trabajo Social de la Pontificia Universidad Católica de Valparaíso. Correo electrónico: sandra.iturrieta@pucv.cl
} 


\begin{abstract}
In the context of the society of uncertainty, of the massive circulation of information and of the instantaneity of communications, which are shaping new virtual subjectivities, which forces us to broaden the notion of direct social intervention, from face-to-face relationships. Towards the inclusion of technosociability, those who work in the field of direct social intervention, send messages to future generations of social work professionals. These messages were obtained through qualitative research at the national level, which contemplated the development of life stories of such professionals. The sense of simplicity, friendship and affection, expressed in interviews with future generations of the profession, allows these messages to be assimilated to exemplary letters that respond to the master-disciple binomial and take the persuasive function as predominant function. This article gives an account of the values, professional traditions and orientations for action, offered by social work professionals who currently make up the student world of the discipline, in an increasingly reticular society.
\end{abstract}

Keywords: Uncertainty, reticular society, letters to students, social work, direct and indirect social intervention.

\title{
Antecedentes
}

Lejos de la intencionalidad de incursionar en los campos de la epistología, y de las formalidades con las que se instruye la escritura de cartas: fecha y lugar en que se escribe; encabezamiento y despedida, acompañados de un adjetivo para calificar a la persona destinataria del breve escrito (Horcas, 2013), la idea de carta es usada en este texto en sentido laxo. Con ella se alude a un intento de transmitir un mensaje a través de letras, dada la lejanía entre quien escribe y quienes recibirán la comunicación. Sin embargo, no se trata solo de una vía para sustituir la presencia, sino que estas cartas, siguiendo la idea de Séneca, tienen una finalidad pedagógica, ya que "responden al binomio maestro-discípulo y toman como función predominante la persuasiva." (Horcas, 2013, p.15).

Según la historia del género epistolar, ofrecida por Horcas (2013), las cartas habrían estado al servicio de la realeza y ejércitos: Ejemplo de ello, son las epístolas de Heródoto a la administración persa en el siglo V a.C. Sin embargo, se tiene constancia de que en Egipto alrededor del 1500 a.C., existían las cartas modélicas dentro del seno educativo.

Con finalidades públicas, privadas, o educativas, la producción epistolar se masificó de modo tal, que se hizo necesario dictar normas que las formalizaran y regularan, para ello se crearon formatos estándares. No obstante, hacia finales del siglo XV e inicios del XVI, los tratados del arte epistolar rompen con los antiguos cánones latinos para la escritura de cartas, interesándose en el contenido y estilo, e imponen una forma de escritura "humilde y sencilla, como si estuviéramos enfrente de la persona a la que escribimos" (Horcas, 2013, p.16). Ese había sido el sentido argumentado por Demetrio, que propone una caracterización propia del género epistolar, basada en "la sencillez que debe rodear todo el 
escrito, a la brevedad de la que debe ser partícipe un texto que se corresponde con un testimonio de amistad y a la revelación del carácter del escritor por medio de la carta, convirtiéndose el escrito epistolar en el reflejo del alma de quien escribe" (Horcas, 2013, p.14). A las funciones de las cartas definidas por Séneca y por Demetrio, se agrega que, para Cicerón, tienen un fin informativo de la vida diaria entre amistades, mientras que para Símaco, las epístolas estarían vinculadas al afecto y sentimientos amistosos, donde la brevedad que las caracterizaba, es revertida con la idea de que la longitud de la carta debe ser proporcional al asunto y al afecto hacia la persona destinataria: "cuanto más larga es la carta, mayor será el afecto mostrado al destinatario" (Horcas, 2013, p.15).

El sentido de sencillez, amistad y afecto, expresado por profesionales del trabajo social hacia las futuras generaciones de la profesión, junto a la idea de modelamiento educativo, es lo que permite llamar "cartas" a los mensajes dirigidos a quienes actualmente se están formando en la carrera, y que conforman un grupo destinatario real y concreto de las palabras como expresión de aquello que, producto del ejercicio laboral, se quiere transmitir como experiencias subjetivas, a la vez que consideradas útiles, por profesionales del campo de la intervención social directa, que a lo largo del país "dictaron cartas a una escribana", dirigidas al mundo estudiantil del trabajo social en Chile.

Entre los años 2017 y 2019 se ha desarrollado una investigación sobre las subjetividades con que profesionales de antropología, psicología, sociología y trabajo social, que se desempeñan laboralmente en el campo de la intervención social, experiencian su ejercicio profesional. Dentro de los criterios de inclusión para la selección de informantes, se consideró que fuesen profesionales de dichas carreras, y que tuvieran a lo menos un año de experiencia laboral en intervención social directa.

Se entrevistó presencialmente a 54 personas a lo largo de todo Chile, desde Arica a Punta Arenas, empleando como técnica de recolección de datos, relatos de vida. Como punto de inicio, se pidió a estas personas que relataran su vida laboral desde que comenzaron en el campo de la intervención social directa, hasta el momento de la entrevista. A modo de cierre de estas sesiones, se pidió a cada cual que enviara un mensaje a quienes, en estos momentos, se están formando como profesionales en el campo de las ciencias sociales. De los mensajes correspondientes a trabajo social, da cuenta el presente texto, que intenta seguir los planteamientos de Demetrio quien propone "el uso de proverbios y refranes como elementos embellecedores de una carta, puesto que presuponían también la manifestación de la sabiduría popular" (Horcas, 2013, p.14). En este caso como expresión de sabiduría profesional, se han escrito de modo fiel las expresiones de que quienes "dictaron estas cartas". 


\section{Intervención social directa e indirecta en la sociedad reticular}

Como fue puntualizado con anterioridad, las personas participantes en esta investigación corresponden a profesionales del campo de las ciencias sociales, que se desempeñan en intervención social directa.

A lo largo de los años, la intervención social ha sido clasificada de diferentes modos. Entre ellos, se la ha agrupado conforme a la relación presencial / no presencial entre profesionales y personas destinatarias de sus trabajos, caracterizándola de acuerdo con diferentes ámbitos de desempeño; conforme las actividades, técnicas y estrategias profesionales para alcanzar determinados logros; siendo la relación cara a cara, la más significativa para establecer la clasificación del tipo de intervención de la que se trata, puesto que se reconoce en este tipo de relación, influencia y compromisos mutuos, siendo de responsabilidad profesional, la acción social y el uso de técnicas y estrategias para lograr la potenciación de los recursos que poseen las personas para enfrentar situaciones adveras y aprovechar la oportunidades sociales. (COTS-Madrid, 2003; ANECA, 2005; Puig, 1988; Fernández y Ponce de León, 2006)

Mientras que la intervención indirecta correspondería a aquella desarrollada en beneficio de las personas destinatarias del trabajo profesional, pero sin su presencia ni participación activa durante el desarrollo de actividades profesionales, tendientes a acercarles los recursos disponibles en sus entornos; durante la creación de nuevos recursos, y durante el diseño de acciones para aumentar el bienestar personal y social.(COTS-Madrid, 2003; ANECA, 2005; Puig, 1988; Fernández y Ponce de León, 2006) Ello en el entendido que la noción de recursos, alude a una amplia gama de lo personal y simbólico, mucho más allá de lo meramente material.

Una mirada crítica respecto de la intervención social directa e indirecta, es ofrecida por Taobada (2008), quien plantea que la primera apunta a actuaciones profesionales realizadas en estrecho contacto con las personas con las que se trabaja. La autora propone que, en esta definición no debieran incluirse modos de actuación profesional, ni formas de entender la relación entre profesionales y personas destinatarias de sus trabajos. Como tampoco, las materias que son objeto del trabajo que se ejecuta, ya que, según su visión, lo único que define este tipo de intervención es "que se realiza un encuentro entre sujetos (colectivos o no) y profesionales" (Taobada, 2008, p174). Desde tal punto de vista, la diferencia entre la intervención social directa e indirecta, estaría dada en que los objetivos de la primera se enfocarían hacia personas concretas, o grupos que tienen necesidades o intereses también concretos. Mientras que, en la intervención social indirecta, los objetivos están dirigidos a personas inespecíficas, independientemente que 
conozcan o no, comprendan o compartan, las finalidades que guían las actuaciones profesionales, pudiendo beneficiarse de ello en cualquier momento, sin ningún tipo de relación con quien interviene profesionalmente. (Taobada 2008). Desde esta perspectiva, lo que marcaría la diferencia entre intervención social directa e indirecta, sería que, en esta última las personas destinatarias de los trabajos, "no determinan el cambio de la situación; este cambio obedece, en sus resultados, a la determinación profesional de quien ejerce el trabajo social" (Taobada, 2008, p.177).

La discusión ético-política que suscitó el concepto de intervención asimilado a intromisión y más allá de la sinonimia, vinculado a matrices epistemológicas positivistas y autoritarias, que llevó a distintos sectores de la profesión a conceptualizar el trabajo profesional, como actuaciones profesionales (Restrepo 2003), o como acción social situada y con sentido, desde una perspectiva weberiana, parece haber quedado lejos tanto de las aulas universitarias como del ejercicio profesional. Actualmente, tal discusión no corresponde a un tópico que ocupe grandes volúmenes de páginas, como en un momento de la historia del trabajo social latinoamericano lo hizo. No obstante, para darle sentido, necesitamos nombrar aquello que hacemos y que se constituye junto a la investigación social, en el quehacer del trabajo social contemporáneo. El corolario de todo aquello es que continuamos usando la noción de intervención social directa o indirecta para caracterizar una parte de nuestras actividades profesionales. De allí que surja la necesidad de contextualizar en la actual sociedad reticular, la idea de ser profesional del campo de la intervención social directa.

La sociedad reticular se caracteriza por la circulación masiva de información variada y disponible para amplios sectores de las sociedades, y por la instantaneidad de las comunicaciones, que van conformando redes que posibilitan la sociabilidad entre personas distantes en el tiempo y en el espacio, que intercambian no solo información concreta, sino también símbolos y significados conceptuales y miméticos. La cotidianeidad se ve entonces atravesada por interacciones entre personas de múltiples orígenes geográficos, ideológicos y culturales que coexisten, y que van generando diversos escenarios individuales y/o colectivos. (Nihil 2016) De esta manera, este incesante flujo de información circulando por todo el planeta de modo instantáneo, provoca nuevos entornos, nuevas dimensiones, y también nuevas inclusiones/exclusiones (Muriel 2006), además, de profundas transformaciones en los modos de entender y vivenciar la relación espacio/tiempo en que se desarrollan las experiencias humanas. Se generan nuevas prácticas sociales, configuradas por relaciones múltiples entre el espacio/tiempo, que a su vez van creando estrategias de intercambio entre actores sociales, nuevos significados y valores identitarios que orientan las prácticas a partir de estas "tecnosociabilidades". (Nihil 2016) La sociedad reticular por 
tanto se caracteriza por la existencia de nuevos modos de interacción cultural, política y social, y por formas de comunicación cada vez más diversas, donde se generan nuevos juegos relacionales, y la "afirmación de las identidades sociales mediante una especie de destrucción creativa de las solidaridades precedentes; creación y gestión de las características de «pertenencia » de las personas, no como construcción de relaciones sobre bases estables o adscriptivas, sino como continua negociación de relaciones elegidas mediante recorridos que no corresponden a lógicas funcionales o de la primera modernidad; crecimiento de formas asociativas, y también "grupales», que mezclan y combinan entre sí elementos informales y formales en el uso y consumo de las relaciones. (Herrera y Alemán, 2006, p.231)

La sociedad reticular implica, por tanto, que las metodologías y los nuevos perfiles profesionales del trabajo social, deban considerar estos nacientes modos de existencia (Herrera y Alemán, 2006, p.231), y las subjetividades virtuales que se construyen vinculadas a procesos de cambio en la definición de lo público y lo privado, cuyos límites se desdibujan, articulándose con el desarrollo de identidades flexibles, (Samela,2018), en un mundo de incertidumbres. (Beck, Giddens y Lash 2001)

De modo que, en la noción de profesional de la intervención social, habría que incluir el trabajo que se desarrolla a través de las más diversas redes sociales, porque hoy corresponde a un trabajo invisible, que ocupa parte del quehacer inmaterial del trabajo social, y además porque la sociedad reticular implica la configuración de nuevas subjetividades que forman parte del trabajo profesional. En razón de ello, ampliaremos la noción de intervención social directa, desde las relaciones cara a cara, hacia la inclusión en tal concepto, de los vínculos que se generan entre profesionales y personas destinatarias de sus trabajos a través de la tecnosociabilidad. 


\section{Cartas a estudiantes de trabajo social en contextos de incertidumbre y subjetividades virtuales}

Tal como argumentan los sociólogos de la modernidad reflexiva, la pérdida de las tradiciones y de los metarrelatos; los cambios de los valores sociales; el riesgo ambiental; y la amplitud de opciones que ofrece la sociedad del conocimiento, convierten a la incertidumbre en un factor social transversal. (Giddens, 1996; Beck, 2002; y Bauman; 2008). La incertidumbre también se vive en relación al futuro, ya que por una parte existe mayor autodeterminación y diversidad de oportunidades, pero ello es vivido como pérdida de orientación, lo que conduce a una demanda de redes sociales vinculantes, que generen pertenencia y sentido de vida. (Beck 2006) Por tanto los nuevos modos de vida, así como los de trabajar, se viven como una especie de inseguridad existencial, es decir, propia de la experiencia de ser humanos y vivir en sociedad, Bauman (2008) con subjetividades permanentemente impactadas por la tecnosociabilidad, y donde cada persona debe forjarse su futuro sin las orientaciones que las tradiciones otorgaban. De manera que la incertidumbre permea diversas dimensiones a la sociedad, ya que a pesar de que las ciencias nos han plasmado en cierta medida de algunas certezas, han generado a su vez un sin número de incertidumbres, dado que el conocimiento es inacabado. En otras palabras, "aunque conservemos y descubramos nuevos archipiélagos de certidumbre, debemos saber que navegamos en un océano de incertidumbre" (Morín,1999, p.76).

Es en este contexto, que quienes ejercen el trabajo social en intervención social directa, a lo largo de todo Chile, hablan a estudiantes que en el futuro ocuparán los campos laborales de la profesión:

\section{A quienes estudian trabajo social...}

Ante malas experiencias, "no pierdas los convencimientos... muchos te van a decir "no seas buena persona en tu trabajo, no hagas esto o esto otro, no hagas estas cosas porque la gente no es buena", pero... pero ahí viene el tema de tus convencimientos, debes seguir siendo la misma persona, no un trabajo, una mala experiencia laboral te va a cambiar, por ende, tu compromiso social frente a las personas con las cuales trabajas se mantendrá intacto". (Profesional de trabajo social, zona central de Chile). Pero "ten cuidado con esto de salir con la capa de súper héroe... en la medida que vayas teniendo experiencias, te irás enfrentando a una realidad que muchas veces es desalentadora, frustrante, pero en la medida que tengas ciertas convicciones claras, se convertirán en alicientes, en un piso de base para continuar en esto, que claro... en términos del tipo de sociedad que hemos construido, no siempre se cumplirán tus expectativas en las distintas esferas en términos del éxito, de lo económico... pero son las convicciones las que te irán moviendo." (Profesional de trabajo social, zona sur de 
Chile). "Piensa que mucha gente te puede decir que trabajo social es una carrera hermosa y que tiene esto y lo otro, y nosotros/as los/las trabajadores/as sociales tenemos una mezcla de todo, tenemos harta psicología, vemos ámbitos de antropología, sociología, tenemos una mezcla de líneas para trabajar, la diferencia es que nosotros tenemos esa capacidad de poder entregársela a las personas, los grupos, a los casos, la comunidad, entonces es una carrera entretenida, tiene de todo un poco, bastante lectura, y conocimientos... así que motívate a seguir trabajando, a seguir transformando, a generar cambios porque no son imposibles, son totalmente reales y hay mucha gente que puede dar fe de eso." (Profesional de trabajo social, zona sur de Chile) Pero para eso, "créete el cuento, anda a pararte en un sector con seguridad... y también ten tolerancia a la frustración con los dirigentes sociales, con los vecinos..." (Profesional de trabajo social, zona norte de Chile). "Tienes que tener un nivel de tolerancia... muchas cosas no te van a salir como tú quieres que te salgan, las personas no van a generar un cambio como el que tú tienes previsto para que su vida mejore, entonces genera un nivel de tolerancia a la frustración, eso es algo que debes tener bien trabajado, o empieza a incorporarlo porque es algo con lo vas a estar en el día a día." (Profesional de trabajo social, zona central de Chile) "Desarrolla un alto nivel de tolerancia... a las personas, a la frustración." (Profesional de trabajo social, zona central de Chile)

Sé perseverante, "sé muy perseverante, muy perseverante, porque si apostaste por esto y si es por vocación, vas a vivir tu trabajo con sentido, y el sentido que tendrá es que te dirás: vale la pena en el fondo todas estas frustraciones o ansiedades, por eso sé muy perseverante, porque el ámbito laboral está difícil, hay muchos profesionales, los espacios laborales están muy acotados... entonces, no te desmotives". (Profesional de trabajo social, zona central de Chile) "No te rindas... porque te desesperarás, pasarás mucho tiempo buscando trabajo... te frustrarás mucho, porque es difícil, sobre todo cuando sales y no tienes experiencia... y todos te la piden... entonces es difícil, pero finalmente se logra, entonces sé muy perseverante." (Profesional de trabajo social, zona central de Chile) "No te conformes... cuándo tú veas que las cosas no van a favor de lo que estás trabajando, no te conformes y no tengas miedo de que nada puede cambiar, ve que sí se han conseguido cosas, sí se han visibilizado cosas... verás que se logró un gran avance... bajaron los niveles de estrés de todos... hubo más sonrisas." (Profesional de trabajo social, zona central de Chile) "Cree en que hay cosas que deben seguir cambiando, no llegues a un lugar y digas: "no hay nada que hacer", porque estarás perdido/a, no tengas miedo, no te quedes ahi sin hacer nada." (Profesional de trabajo social, zona central de Chile) 
"Confía en ti... confía en ti, no te quedes con lo que te dice el sistema, no te quedes con las limitaciones, siempre anda más allá, piensa que sí se pueden lograr cosas, si lo planteas y lo objetivas bien, se pueden lograr cosas, entonces no te quedes con las trampas del sistema... plantéate bien en lo que vas a hacer, y co-construye algo, busca, sé insistente... sé "insistente social." (ríe) Por ejemplo, el trabajo administrativo es una trampa del sistema, porque te quedas ahí y es difícil poder hacer otras cosas, darle la importancia que merece la intervención... otra trampa del sistema es que también tendrás que lidiar con otros profesionales, que a lo mejor no tienen el mismo enfoque social, pero eso tienes que ir contra la corriente constantemente." (Profesional de trabajo social, zona norte de Chile) Piensa que "sí se puede, al final cuando a veces te quedas en la queja y en la desesperanza, obviamente no vas a generar impacto en las personas, porque si tú mismo/a no crees en lo que estás haciendo, ¿cómo vas a convencer al otro/a? Y si, además, esas personas lo han pasado pésimo, o sea, vienen desde la desesperanza máxima... con muchas vulneraciones sociales, afectivas, económicas, de todo, entonces lo que les puedes entregar, es el convencimiento de que efectivamente puede haber un cambio, que esa cicatriz o la herida en algún momento ya no va a doler, que vamos a aprender, y a lo mejor esa herida va a ayudar a sobreponerse, y a mirar hacia delante de porque vienen cosas positivas." (Profesional de trabajo social, zona norte de Chile)

Sé humilde, "no pierdas lo que te llevó a estudiar la carrera... conserva la esencia, o sea, no porque estés en un cargo, que tengas el título... quizás llegues después ser jefe/a..., perderás la esencia de lo que creías cuando estabas estudiando, en la práctica no te gustaba que te miraran en menos, entonces que no lo hagas tú: "que la vaca nunca se olvide que fue ternero". (Profesional de trabajo social, zona sur de Chile) Existe la visión de que el/la profesional casi nació de cuna de oro, y no es así, hay profesionales que venimos de abajo, y logramos un cargo, pero es a base de esfuerzo." (Profesional de trabajo social, zona sur de Chile) "Lo importante cuando estás estudiando una profesión de esta índole, que es una de las más bonitas para la vida de una persona, es analizar el origen de uno, honrar el origen, es importante que no te sitúes desde el lugar de experto/a, sino de una persona que va a aprender trabajando en intervención. Van a pasar muchas cosas que son importantes de revisar, por eso es muy sabio para las/los que recién egresan, comprender que en realidad tú tienes la parte del conocimiento académico, pero hay que reconocer que las personas también te pueden enseñar algo, entonces es necesario que seas humilde y te sitúes de sujeto a sujeto." (Profesional de trabajo social, central de Chile) 
Actúa con respeto, "debes respetar de donde viene la persona, sus creencias, su cultura, eso de decirle a una persona que vive de la pesca, que toda su vida ha sido pescador y que tiene su casa en la punta del cerro: "oiga usted lo está haciendo mal, oiga usted se tiene que ir, cómo hace eso", o sea, en verdad tienes que concientizar y educar a las personas, pero respeta también de dónde vienen... Si a te carga el olor a pescado, hay gente a la que ese olor le recuerda a sus raíces, los recuerdos más lindos que tienen, entonces no te pierdas con eso... ten siempre respeto de donde están las personas y acompáñalas... al final cuando tienes claro eso, la pega es súper llevadera." (Profesional de trabajo social, zona norte de Chile) "Interésate en lo que quieren las personas con las que tú estás trabajando, porque en realidad trabajarás para programas, trabajarás para empresas, o para lo que sea, donde tus funciones están dadas, y el servicio que tú vas a otorgar para Juan, Pedro, Diego, o María, es el mismo, y eso no es posible, porque todos ellos tienen intereses distintos y necesidades diferentes, eso es súper difícil de internalizar... y ahí tienes que ser lúcido/a. (Profesional de trabajo social, zona central de Chile)

Ten "empatía con la realidad, con las/los sujetos... en realidad lo que queremos en el trabajo social es lograr una transformación a las/ los sujetos ¿cierto?, porque para allá apuntamos, a veces te tocará trabajar individualmente, o colectivamente, pero igual tienes que dejar algo instalado ahí, entonces eso te agotará, no es fácil, entonces tienes que estar constantemente con ánimo, siempre positivo/a ¿ya?, tienes que mantener la disposición, después tendrás tu espacio para despotricar, tu espacio más interno, pero delante de la gente no... tienes que tener respeto por la gente." (Profesional de trabajo social, zona central de Chile) Piensa que la empatía es lo primero, el no juicio... piensa que en el fondo la persona siempre está en el centro, que nosotros no somos salvadores/as, ojalá tuviéramos una varita mágica, porque a veces la gente piensa eso... no está muy claro para la gente qué es ser trabajador/a social... hay gente que piensa que está ligado a terapia ocupacional, como que la gente no sabe mucho, entonces nosotros/as somos los/las encargados/as de dar a conocer cuál es nuestra tarea." (Profesional de trabajo social, zona sur de Chile)

Sé responsable, "nunca olvides que trabajamos con personas, con comunidades y muchas veces el desarrollo del micro espacio social, está en nuestras manos." (Profesional de trabajo social, zona sur de Chile) Resguarda los procesos, cumple con las metas, pero no dejes de lado los procesos. (Profesional de trabajo social, zona sur de Chile) Piensa que "hay tiempo para tomarse el café en la oficina, pero que el café sea eso, no saques la vuelta, no tengas excusas para sacar la vuelta, sino que el café sea una pausa activa." (Profesional de trabajo 
social, zona sur de Chile) "Intenta dividir tu tiempo lo mejor posible, sé ordenado/a, en el sentido de organizarte con las cosas, porque trabajar en intervención directa es algo muy rico, algo muy grato, lo pasarás bien con las personas que estás ayudando y todo eso, pero la cantidad de trabajo administrativo es muy grande." (Profesional de trabajo social, zona central de Chile) "Sé responsable con las personas, porque tú tienes los conocimientos teóricos y prácticos para poder aportar en distintos lugares y si eso lo ocupas para otras cosas, terminarás haciendo daño, terminarás inventándole cosas a la gente... desde lo político partidario, hasta lo que son los estilos de vida." (Profesional de trabajo social, zona central de Chile).

Ama lo que haces, ama lo que haces... eso significa... ser responsable con nuestra labor profesional, primero sé responsable con tu labor formativa, has los mejores trabajos, has las mejores evaluaciones, preocúpate de eso... en la universidad hay tiempo para todo, tiempo para pasarlo bien, para pololear, para carretear, y también tiempo para estudiar. Has todo lo que estimes conveniente, siempre que sean los patrones adecuados, socialmente aceptados, todo lo que sea conveniente, todo lo que estimes, todo lo que quieras hacer de manera seria, responsable y con amor, como sociedad nos falta amor, y siempre piensa en perspectiva todo lo que vayas a hacer, por ejemplo: cómo eso repercute en tu vida profesional, en la vida del otro." (Profesional de trabajo social, zona sur de Chile) Estudia, aprende y date cuenta que la realidad no es una sola, son muchas, son muchas..." (Profesional de trabajo social, zona central de Chile).

Actúa con compromiso, "eso es muy importante, si vas a asumir un compromiso trata de cumplirlo, vive las cosas, equivócate, porque si no te equivocas nunca vas a aprender, en el acierto siempre vas a estar en una zona de confort, en la equivocación es donde viene todo el proceso que te ayuda a cuestionarte, a darte cuenta que tus defensas, o que tus conocimientos, con ganas de absorber, de darte cuenta, de poder aprender más." (Profesional de trabajo social, central sur de Chile).

Desarrolla tu capacidad de adaptación porque "lo más importante es conocer y saber cuál es la población con la cual vas a trabajar, has un diagnóstico, conoce y adáptate tú a la gente, no que la gente se adapte a ti, tienes que ser el/la encargado/a de que la información llegue a las personas de la manera más asertiva o... que llegue de la mejor manera, tú eres quien tiene que buscar las formas, las estrategias, de cómo lo vas a hacer, pero para saber cómo hacerlo, tienes que conocer a las personas con las que vas a trabajar, saber que si llevas un montón de textos en diapositivas la gente se aburre, isi algunos no 
saben ni leer! (Profesional de trabajo social, zona sur de Chile) "Te va a ir mucho mejor si eres una persona cercana, pero cercana de verdad, no cercana de ser cariñosa/o con los/las demás, sino que cercana en cuanto a que puedas hacer un trabajo más horizontal." (Profesional de trabajo social, zona central de Chile).

Infórmate y "ten conocimientos de algunas materias transversales... la basura, es un tema país, es un tema transversal... también cómo vamos construyendo las casas, murallones delante de las casas por el tema de la delincuencia, entonces... anda haciendo esos análisis, de como nosotros vamos hablando de un tema... hablando de un modelo, de alguna forma de poder intervenir, desde algún enfoque... también cuestiona esos enfoques..." (Profesional de trabajo social, zona norte de Chile).

Participa, "Sí vas a hablar de las redes, anda a hacer una visita guiada por las distintas redes de tu territorio, participa en las Juntas de Vecinos, has uso de los programas de gobierno, participa en la iglesia, participa en los scouts, o donde sea, pero participa." (Profesional de trabajo social, zona norte de Chile).

"No pierdas lo humano que tiene el trabajo social, a veces te encontrarás con profesionales, que no te mirarán ni a los ojos y con eso ya te das cuenta que no están ni a hí con lo que hacen, como que al final su trabajo es solo un medio para lograr otras cosas." (Profesional de trabajo social, zona central de Chile) "Date cuenta que más allá de eso de las lucas, no hay que perder lo otro, si al fin y al cabo tú estás trabajando con la gente y la gente ya viene con hartos problemas, inclusive tú mismo/a en tú proceso de vida, tal vez vienes con hartos problemas visualizados." (Profesional de trabajo social, zona central de Chile) Date cuenta además de que "estudiar cualquier carrera vinculada al área de las ciencias sociales, es un desafio porque somos gente que está viendo las cosas, estamos llenos de sueños, de rabia o de frustraciones de decir: "me gustaría cambiar estas cosas, a mí no me parece justo que esto ocurra asi" y desde ahí no tienes que perder la humanidad entre nosotros como profesionales también." (Profesional de trabajo social, zona central de Chile).

Reflexiona sobre tu vocación, "detente... detente... reflexiona si realmente lo que estás estudiando es lo que quieres, en lo que te visualizas y te proyectas para hacerlo toda tu vida, si realmente quieres servir a otros, si es algo que te llena, si se dan cuenta que sirves a tu familia, a tus amigos, a tus vecinos, a la gente que tienes en su entorno, si se dan cuenta que eres feliz haciendo eso con tus seres queridos, y además quieres especializarte técnicamente para hacerlo bien, estás 
bien ubicado/a. Por el contrario, hay personas que a lo mejor tienen mala relación con su entorno... si te da lo mismo lo que le pasa al otro, si no tienes incorporados valores de solidaridad, de justicia, yo creo que se debieses detenerte y repensar, repensar... no todos tenemos que ser buenos para todo, no todos servimos en todo, y que rico que así fuera, pero no podemos ser todos trabajadores sociales, la vida está llena de diversidades, de riquezas... Te invito a mirarte... a mirarte, a detenerte a ver si realmente te gusta y te hace sentido en lo que estás, si no te da lata leer un texto de psicología, si no te da flojera estudiar para una prueba de psicología social evolutiva de etapas de desarrollo, si te gusta ir a tus prácticas, las primeras, detente en lo que te está pasando a ti como persona, porque esta es una carrera como persona, las herramientas claramente sirven, pero en el trabajo con personas... uno se entrega como persona. (Profesional de trabajo social, zona sur de Chile).

Profesionales del Trabajo Social

en intervención social directa. 


\section{Reflexiones finales}

Según el epistolario español de 1861, "las palabras pronunciadas se olvidan con el paso del tiempo porque, al fin y al cabo, las palabras, palabras son. Pero no ocurre igual con aquellos pensamientos que se plasman en el papel, que volverán a la mente, con la misma intensidad, cada vez que se relean." (Horcas, 2013, p.17). Este es el sentido de haber puesto por escrito los pensamientos que profesionales del trabajo social desempeñándose en intervención social directa, han elaborado durante el desarrollo de sus relatos de vida, para enviarlos a quienes se perfilan hoy como el futuro de la profesión en Chile.

Conscientes de que en la sociedad reticular se generan nuevos entornos, nuevas dimensiones y también nuevos sistemas de inclusión/exclusión, y donde la relación tiempo espacio ha cambiado, tales profesiones se dirigen a quienes estudian trabajo social, hablándoles de convicciones; tolerancia; perseverancia; autoconfianza; humildad; respeto, y empatía. Les recomiendan actuar con criterio de realidad; estudiar y respectar la diversidad. Amar y ser responsables con su formación profesional y con el trabajo. Igualmente, les instan a actuar con compromiso; a equivocarse y a aprender de aquello; a tener sentido de la organización; capacidad de adaptación, y conocimientos transversales. Finalmente, les invitan a ser coherentes y participar socialmente; a desarrollar un trabajo horizontal y con sentido, y a reflexionar sobre su vocación. Todo ello refleja tradiciones y valores del trabajo social, además de orientaciones para la acción profesional.

De modo que en medio de la incertidumbre social y del impacto de la tecnosociabilidad en las subjetividades, quienes se están desempeñando en el campo de la intervención social directa, juzgaron como necesario relevar ciertos valores profesionales tales como la humildad, el respeto, la responsabilidad, la tolerancia, y el compromiso social, que sumados a los valores sociales de justicia y solidaridad, corresponderían a aquellos que debiesen ser salvaguardados por quienes se están formando para ejercer la carrera de trabajo social en el futuro.

A la par, las personas entrevistadas en esta investigación, aun cuando igualmente se encuentran inmersas en la sociedad de la incertidumbre, realzan ciertas tradiciones del trabajo social, que podrían ser consideradas como preceptos orientadores del quehacer profesional. Entre tales tradiciones profesionales se encuentra la necesidad de generar cambios sociales; la valoración positiva de la amplitud disciplinar del trabajo social; la importancia del pensamiento crítico social frente al sistema neoliberal; y la convicción de que el cambio es necesario y posible. Mientras que en el ámbito de las relaciones con las personas destinatarias del trabajo profesional, se realza la necesidad de actuar con empatía y consideración a las diversidades sociales y culturales, desarrollando una labor profesional contextual, teórica y éticamente situada. 
Igualmente, quienes han participado en esta investigación, entregan algunas orientaciones para la acción profesional, que podrían contribuir a sobrellevar la incertidumbre, y a incorporar los nuevos juegos de relaciones que provocan subjetividades virtuales, influyentes en la intervención social directa e indirecta, que el trabajo social desarrolla en la sociedad reticular. Entre tales orientaciones para la acción, destacan las ideas referidas a creer en que las situaciones adveras que forman parte de la realidad social actual puede ser cambiada, por lo tanto, habría que trascender a las quejas constantes y a las desesperanzas, conservando el optimismo y la esencia de la elección del trabajo social como opción profesional, situándose como alguien afable, que aprende de las personas y sus contextos, que cumple las metas impuestas pero que a la vez resguarda los procesos sociales que subyacen a aquello. Por lo tanto, la organización de las labores y sus respectivos tiempos de ejecución deben ser siempre observadas, junto a los impactos que las actuaciones profesionales autogeneran y producen en las otras personas. Siendo necesario además conocer a las personas y contextos con los que se trabaja, desarrollar la capacidad de tolerancia a la frustración, revisar y reafirmar la vocación profesional y dar a conocer la impronta profesional y disciplinar del trabajo social a la sociedad.

Finalmente, una parte de las subjetividades profesionales son expresadas en estos mensajes a quienes están estudiando trabajo social, a través de proverbios, que transmiten tradiciones de la profesión, que cotidiana y recurrentemente son aludidas a modo de consejos o enseñanzas y que contienen lo más profundo del ethos del trabajo social en lo relativo a la intervención social: "ojalá tuviéramos una varita mágica", como anhelo de transformación social. "No salir con la capa de súper héroe": como expresión de la necesidad de autocuidado y de la conciencia de límites. "Creerse el cuento", es la invitación a la necesaria autoconfianza que el ejercicio profesional requiere. Ser, "insistentes sociales" en lugar de asistentes sociales, como manifestación de la perseverancia que el trabajo en contextos complejos requiere, y "que la vaca nunca se olvide que fue ternero", como un llamado a preservar la humildad, aun cuando en el contexto social actual, el éxito individual sea valorado como símbolo de integración social y de bienestar subjetivo, y por tanto deseado. 


\section{Referencias bibliográficas}

Agencia Nacional de Evaluación de la Calidad y Acreditación (2005). Libro Blanco. Título de grado en Trabajo Social. Recuperado de http://portal.uned.es/

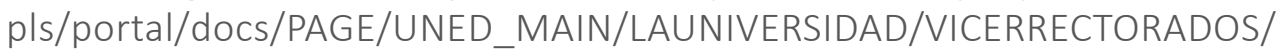
ESPACIOEURO/LIBROS\%20BLANCOS\%20DE\%20GRADO/LIBROBLANCO_ TRBJSOCIAL_DEF.PDF

Bauman, Z. (2008). Tiempos líquidos: Vivir en una época de incertidumbre. México: TusQuest.

Beck, U. (2002). La sociedad del riesgo. Hacia una nueva modernidad. Barcelona: Paidós.

Beck, U, Giddens, A. y Lash, S. (2001). Modernización reflexiva: Política, tradición y estética en el orden social moderno. Madrid: Alianza.

COTS-Madrid (2003). Manual para el trabajo social de acompañamiento. Colegio oficial de trabajadores sociales de Madrid.

Fernández, T. y Ponce de León, L (2006). El proceso de intervención en el trabajo social con casos: una enseñanza teórica-práctica para las Escuelas de Trabajo Social. Recuperado de https://dialnet.unirioja.es/servlet/ articulo? codigo $=2002376$

Giddens (1996). Las consecuencias de la modernidad. Madrid: Alianza.

Herrera, M. y Alemán, C. (2006). La intervención social en una "sociedad" reticular. Papers. Revista de Sociología, 81, 229-247. Recuperado de https://dialnet.unirioja.es/servlet/articulo?codigo=2248717

Horcas, J. (2013). Las epístolas femeninas en la literatura: Espejos borrosos en una sociedad de orden patriarcal. Fundación Universitaria Andaluza Inca Garcilaso. Recuperado de http://www.eumed.net/librosgratis/ciencia/2013/20/index. htm

Morín, E. (1999). El método, tomo III: El conocimiento del conocimiento. España: Cátedra.

Muriel, D. (2006). (In)transitabilidades hacia la sociedad del conocimiento: una lectura crítica de la producción sociológica moderna. CONfines de relaciones internacionales y ciencia política, 1 (2), 19-34. Recuperado de http://www.scielo.org.mx/scielo.php?script=sci_arttext\&pid=S187035692005000200002\&lng=es\&tlng=es 
Nihil, M (2016). E-migrantes: espacios tecnológicos, geográficos y sociales. ¿Nuevos actores y espacios de participación política? En Rivoir, A. (coord.) Tecnologías digitales en sociedad: Análisis empíricos y reflexiones teóricas. Montevideo: Universidad de la República. Facultad de Ciencias Sociales. Departamento de Sociología.

Puig, C. (1988). La planificación y la programación de la acción social: El proceso metodológico: aproximacióna la realidad, definición del problema, prioridades, programación, ejecución- técnicas de intervención y evaluación. Recuperado de https://www.academia.edu/7843272/LA_PLANIFICACI\%C3\%93N_Y_LA_ PROGRAMACI\%C3\%93N_DE_LA_ACCCI\%C3\%93N_SOCIAL

Samela, G. (2018). Subjetividades virtuales. Universidad de Buenos Aires. Facultad de Ciencias Sociales. Teseopress. Recuperado de https://www.teseopress. com/subjetividadesvirtuales/

Taobada, M. (2008). Significado y diferenciación entre intervención directa e intervención indirecta. Documentos de trabajo social N²43-44. Colegio Oficial de Diplomadas y Diplomados en Trabajo Social y Asistentes Sociales de Málaga. Recuperado de https://dialnet.unirioja.es/servlet/articulo?codigo=2987179

Vélez, O. (2003). Reconfigurando el trabajo social. Buenos Aires: Espacio.

Dirección de correspondencia:

Sandra Iturrieta Olivares

Trabajadora social. Doctora en ciencias sociales, Universidad de Granada, España. Magíster en el análisis de los problemas sociales de las sociedades avanzadas, Universidad de Granada, España. Post doctorado en el estudio de las ideas, Instituto de Estudios Avanzados, Universidad de Santiago de Chile. Académica de la Escuela de Trabajo Social de la Pontificia Universidad Católica de Valparaíso.

Contacto:

sandra.iturrieta@pucv.cl 